\title{
INTRODUCCIÓN GENERAL A LAS LEYES DE PLATÓN Y ESTUDIO DEL LIBRO PRIMERO DE LA OBRA *
}

\author{
Eduardo García Máynez
}

INSTITUTO DE INVESTIGAGIONES FILOSÓFICAS

Universidad Nacional Autónoma de M

\section{INTRODUCCIÓN}

El diálogo las Leyes —obra inconclusa- es el postrero, más extenso y menos estudiado de los escritos platónicos. Se publicó en 347 (año de la muerte del filósofo), por Filipo de Opunte, discípulo y amanuense del fundador de la Academia. ${ }^{1}$ Se ha conjeturado ${ }^{2}$ que el plan del coloquio que no pudo concluir fue esbozado por Platón cuando - según sabemos por la Carta Tercera - ${ }^{8}$ aquél discutía con Dionisio II la conveniencia de anteponer a los textos legales unos "preámbulos" destinados a explicar los motivos determinantes del acto legislativo."

La redacción del largo escrito debe de haber ocupado, cuando menos, la última década de la vida de Platón. Las Leyes son una obra de seneco tud, por lo que no es extraño que adolezca de los defectos que algunos comentaristas imputan a la avanzada edad del hijo de Aristón y Perictiona.s

- Páginas del tomo tercero de la obra Teorias sobre la justicia en los didlogos de Platón (Politico, Leyes y Epinomis).

1 "Filipo de Opunte, secretario y confidente de Platón, que editó y dividió en doce libros, las Leyes después de la muerte del maestro, a base de su manuscrito inacabado, se dio cuenta de la laguna que representaba la falta de la parte relativa a la educación del regente e intentó suplirla concretando a posteriori el carácter de la sabiduría especial que el gobernante necesita. Puso por escrito estas ideas en el estudio que hoy figura como Epinomis o complemento de las Leyes, al final de la obra." W. Jaeger, Paideia, p. 1017 de la traducción española de W. Roces.

2 Cf. Ernest Barker, Greek Political Theory, p. 338.

3 Barker, ibidem.

4 "Pero el preámbulo puede no exponer solamente las razones que llevaron a la adopción del estatuto, sino también, como Platón lo sugirió, fungir como un recurso persuasivo para incitar a la aprobación de la norma legal; servir como recurso hermenéutico destinado a orientar la aplicación administrativa o judicial del precepto $o$, por último, como forma de expresión de la politica legislativa." Huntington Cairns, Legal Philosophy from Plato to Hegel. The John Hopkins Press Baltimore, 1949, p. 52.

5 "Hay en las Leyes - según Barker- una especie de garruleria, y la obra es realmente un monólogo del extranjero ateniense en presencia de dos oyentes que por regla general lo escuchan con paciencia y cortesia". Barker, opus cit., pp. 338-339. 
En el estudio que dedica al extenso tratado, Hermann Gauss señala, entre otras, las siguientes incongruencias: Platón presenta dos diferentes ordenaciones jerárquicas de los bienes, una en el libro I (631 $b-632 d)$, que distingue los bienes divinos de los humanos, y otra en el libro III (697b), según la cual existen tres grupos de bienes: los del alma, los del cuerpo y los "externos". Acerca de los "agrónomos" ofrece, en el libro VI, dos distintas versiones, la primera en $760 a-761 d$ y la segunda en $763 e-764 a$. Cuando, en el mismo libro, se refiere a los matrimonios, fija diferentes edades como las más favorables para la unión de los contrayentes; y, en el libro IX, habla de los tribunales de justicia como de una novedad, olvidando que había ya expuesto el tema en el libro sexto (766 $d$ y siguientes). En las Leyes encontramos también no pocas secciones en que el diálogo desaparece, lo que induce a pensar que se trata de esbozos que no dejaron de ser tales. ${ }^{6}$

Otra censura es que en las Leyes la dosificación temática es a veces desproporcionada. Como prueba principal de tal reproche se invoca el desordenado y excesivamente largo tratamiento del tópico de los banquetes y la embriaguez en los dos primeros libros del coloquio.?

Estas y otras deficiencias, incluso gramaticales y estilísticas, ${ }^{8}$ llevaron a numerosos escritores, durante el pasado siglo, a sostener que las Leyes no eran obra de Platón. Aquellos críticos se esforzaron cuanto les fue posible -afirma Guthrie - "para robarnos las partes más valiosas de los escritos platónicos". No solamente las Leyes, sino el Eutifrón, la Apologia de Sócrates, el Laques, el Lisis, el Carmides, el Alcibiades 1, los dos Hipias, el Menexeno, el Ion, el Eutidemo, el Menón, el Cratilo, el Parménides, el Sofista, el Politico, el Filebo y el Critias fueron considerados como escritos espurios. Parece increíble - declara el mismo Guthrieque los eruditos de la época pasaran por alto el hecho de que Aristóteles recuerda en sus libros, mencionando unas veces el nombre de Platón, otras el título de la obra, otras haciendo referencias que excluyen cualquier duda sobre cuál es el trabajo a que alude, los siguientes diálogos: Fedón, República, Banquete, Menexeno, Timeo, Leyes, Menón, Fedro, Teeteto, Sofista, Filebo, Apologia, Protágoras, Eutidemo, Gorgias, Hipias Menor y Politico. ${ }^{\circledR}$ Incluso Eduardo Zeller, "el más representativo" de los historiadores del pensamiento filosófico en el siglo pasado, no tuvo empacho en declarar - recuerda Jaeger - que "las Leyes no habían sido escritas por el filosofo de la Academia, aun cuando más tarde, en su Historia de

6 Gauss, Handkommentar zu den Dialogen Platos. 2. Hälfte, Kapitel IV, p. 209.

7 Cf. Gauss, opus cit., pp. 209-210.

8 "Los de las Leyes son, en gran parte, defectos de la forma literaria. A la edad de cincuenta años Platón habrla hecho una gran obra con el material que empleó a los ochenta en un trabajo que a primera vista parece mediocre", Barker, opus cit., p. 340.

9 Guthrie, $A$ History of Greek Philosophy, V, pp. 40-41. 
la Filosofia Griega, las Leyes son tratadas por Zeller en un apéndice, con lo que daba a entender que, aunque considerase auténtica la obra, no acertaba aún a encuadrarla dentro del marco general de la filosofía platónica".10 Pese a que aquélla equivale a "más de la quinta parte" de la producción del filósofo ateniense, y a que es, con mucho, su estudio más extenso, "tal estado de cosas indica _prosigue Jaeger - lo poco en serio que se tomaba todavía la necesidad de una comprensión "realmente histórica y fiel" de los diálogos. Los autores se formaban, a su modo, una idea del pensamiento platónico "a tono con la idea preconcebida de lo que entendían por filosofia". El enorme tratado era a sus ojos "una obra secundaria, por no ser ni lógica ni ontologia". Para Platón, sin embargo, representaba algo fundamental, "pues se halla formada por consideraciones muy profundas sobre el Estado y las leyes, manifestaciones todas que supedita al punto de vista general de la paideia". ${ }^{11}$

Este juicio no es una excepción. Otros autores —entre ellos algunos de los más famosos - no sólo reconocen los méritos del largo diálogo, sino que le tributan cálidos elogios. Constantin Ritter, por ejemplo en el prefacio a Platos Gesetze (p. V), escribe: "No vacilo en describir esta obra, junto con la República, como uno de los monumentos más mag. níficos de la cultura de la antigua Hélade y uno de los más finos y admirables libros que conozco"; comentario al que Ernest Barker, en Greek Political Theory (p. 340), añade este encomio: "En riqueza de conocimientos y en la detallada aplicación de los principios a la vida de la época, las Leyes supera a la República". El mismo Barker, al glosar los últimos cuatro libros, dice de ellos que "no sólo son la parte más fina de las Leyes, sino que deben incluirse entre lo mejor de todos los escritos de Platón. Éste es allí, más que un poeta y un filósofo, un legislador y un profeta. Como legislador no sólo sistematiza el derecho griego a la manera de un Bentham, sino que trata, en sus 'preámbulos', de explicar los primeros principios en que su código se basa. Como autor de profecias, en el curso del libro $\mathrm{X}$ llega sin duda con sus expresiones a una altura que dista muy poco de la del más grande de los vaticinadores hebreos. Cuando comenzamos a leer las Leyes, nos decimos a nosotros mismos: 'quantum mutatus ab illo'; pero, al concluir la lectura, no podemos dejar de exclamar: '¡Es Platón todavial; $1 Q u e ́$ no habría podido hacer con este material treinta años antes!" ".12

Interlocutores. "Así como la República empieza con el problema general de la justicia" - escribe Jaeger - la obra póstuma del fundador de la Academia "parte de la consideración del espiritu de las leyes, que en

10 Jaeger, obra y traducción citadas, p. 1015.

11 Idem.

12 Barker, opus cit., pp. 339-340. 
un verdadero Estado infunde su ethos hasta el último detalle". Para ilustrar aquel concepto Platón elige "el tipo de vida política que había atraído siempre su atención: la del Estado dorio. Por eso presenta como interlocutores a dos representantes de esta rama griega: un espartano y un cretense". Fue ésta "una idea feliz", no sólo "porque con ello se aducía un buen ejemplo de cómo una fuerte fisonomía política puede influir en los aspectos materiales de la legislación", sino "porque de este modo se ponía a debate el problema filosófico del 'mejor' ethos del Estado". Pero junto a los dialogantes dóricos, "que obran en lo espiritual como hermanos gemelos", el autor introduce, con el carácter de interlocutor principal, al 'extranjero ateniense', "personalidad misteriosa y soberanamente superior que las otras dos reconocen y acatan de buena gana, a pesar de su marcada aversión contra todo ateniense medio". La elección de las figuras de Clinias el cretense y Megilio el espartano asume -opina el mismo helenista_ "un carácter simbólico", puesto que revela, mejor que cualquiera de los diálogos, la tendencia platónica "a fundir en una unidad superior lo dórico y lo ateniense". 13

El argumento es muy sencillo. El ateniense está de paso en Creta y, hallándose en Cnossos, se propone, como los otros dos personajes, em. prender una excursión a la gruta y al santuario de Zeus. Los tres inician su caminata muy de mañana, y el de Atenas pide a sus acompañantes que "hablando y escuchando cada uno a su vez", se entretengan durante el camino "conversando sobre temas de política y legislación", ${ }_{14}$ a lo que tanto Megilio como Clinias acceden gustosos.

Estructura del coloquio. Auguste Diès, que ha tenido la paciencia de contar los renglones de las Leyes y la República, nos informa que la primera de estas obras, dividida en doce libros, contiene, "en la editio minor de Tauchnitz, 13444 líneas", o sea, 2127 más que los diez libros que componen el otro diálogo. ${ }^{15}$ Según el helenista francés, los doce mencionados pueden, de acuerdo con el plan seguido por el filósofo ateniense, agruparse de esta manera: los tres primeros (con una extensión de 3085 renglones) son algo así como una introducción general. En los dos iniciales, los paseantes discuten algunos aspectos de las legislaciones espartana y cretense (que los griegos tanto alababan por su eunomia), así como las grandes finalidades de la actividad legislativa y la esencia y métodos de las tareas pedagógicas. En el último libro del mismo grupo, tercero del coloquio, se habla del origen de las constituciones y de las enseñanzas que la historia ofrece sobre la índole y sucesión de las prin-

13 Ibidem, pp. 1020-1021.

14 Leyes, $625 a$.

15 A. Diès, Estudio introductorio a la traducción francesa de las Leyes en la Colección Budé. 
cipales formas de gobierno. Casi al final del mismo libro, el cretense Clinias comunica a sus compañeros de caminata que "la mayor parte de Creta tiene el proyecto de establecer una colonia, y ha encomendado a los cnossios la dirección de la empresa, tarea que la ciudad de Cnossos delegó en él y en nueve más". "Se nos ha ordenado - prosigue Cliniasformular leyes, seleccionando las que nos agraden, ya sea entre las nuestras o entre las de otros paises, pero sin preocuparnos por su exotiquez, con tal de que nos parezcan mejores. Dadme entonces, y daos a vosotros mismos esta satisfaccion: espigando entre las cosas que hemos expuesto, construyamos una ciudad por medio del discurso, como si la edificáramos desde su origen". ${ }^{18}$

En el libro siguiente, los interlocutores discuten dónde conviene establecer la nueva ciudad; cuál debe ser su población y qué método ha de seguirse al formular las prescripciones de su ordenamiento legal. En relación igualmente con Magnesia, que es el nombre elegido para la polis que va a crearse, los viajeros se preguntan, en el quinto libro, por el procedimiento que habrá que adoptar al fundarla; por las condiciones que han de reunir sus moradores; por el número y clases de los mismos; por la erección de los templos para el culto a las divinidades y por el tipo de leyes que normarán la vida de los ciudadanos.

El sexto trata con lujo de detalles la forma de elección de los funcionarios, así como los problemas relacionados con la institución del matrimonio. En el libro VII se debate el tema de la paideia; en el que sigue, o sea el octavo, las cuestiones concernientes a las actividades lúdicas y al entrenamiento de los militares, así como las que atañen al comercio y a la economía.

El grupo formado por los libros IX a XI contiene el código de la nueva ciudad, y merece ser visto - según el parecer de Barker- - "como la esencia del diálogo". A la legislación penal se refiere el libro noveno; a la civil, el undécimo. Entre ambos aparece lo que podría llamarse "el libro de las leyes religiosas", en que Platón formula los principios de la verdadera religiosidad y enumera las penas aplicables al delito de herejía. El libro XII es una especie de epflogo; en él se introducen nuevas instituciones políticas y, como afirma el comentarista citado hace un momento, Platón vuelve al idealismo de la República, pese a su aserto de que Magnesia no aspira a ser una polis ideal. ${ }^{17}$

Debido sin duda a la enorme extensión de las Leyes y a la creencia de que la obra no tiene la importancia de la mayoría de las platónicas, los expositores de las doctrinas del hijo de Aristón suelen aludir únicamente, al glosarlas, a los aspectos centrales del tratado, en vez de estudiar,

16 Leyes, $702 c$-d.

17 Cf. Barker, opus cit., p. 339. 
uno por uno y en detalle, los doce libros de aquélla. Entre los historiadores de la filosofía que no intentan un comentario exhaustivo y sólo se refieren a los grandes temas, mencionaremos a Theodor Gomperz, ${ }^{18}$ Constantin Ritter, ${ }^{19}$ Hermann Gauss, ${ }^{20}$ Ernest Barker, ${ }^{21}$ Werner Jaeger ${ }^{22}$ y W. K. C. Guthrie, ${ }^{23}$ cuyo juicio acerca de las Leyes es en muchos puntos favorable.

El autor de este trabajo ha optado, siguiendo el ejemplo de Leo Strauss, ${ }^{24}$ por exponer los aspectos fundamentales de los doce libros en que las Leyes se dividen. Los correspondientes estudios se basan en la traducción directa de los pasajes más importantes de esos libros, que a modo de apéndice aparece, jun'to con los textos del Politico, en la segunda parte del volumen. Para hacer el traslado me serví de la edición bilingüe de la Loeb Classical Library. Tuve a la vista, a fin de cotejarlas con la mía, las versiones francesas de Léon Robin ${ }^{25}$ y Edouard des Places, $^{26}$ y las inglesas de R. G. Bury ${ }^{27}$ y Trevor J. Saunders. ${ }^{28}$ De los comentarios que consulté fueron especialmente útiles para mí los de Gom. perz, Barker, Ritter, Gauss, Jaeger, Guthrie y Strauss arriba citado. En lo tocante a los aspectos filosófico-jurídicos de las Leyes estimo que el estudio más valioso es el que Huntington Cairs dedica a Platón en su libro Legal Philosophy from Plato to Hegel..$^{29}$

18 Cf. Gomperz, Griechische Denker, Vierte Auflage, Walter de Gruyter, Berlin, 1925, Zweiter Band, pp. 486-514.

19 Ritter, Platon. Sein Leben, seine Schriften, seine Lehre. Reprint Edition 1976 by Arno Pres Inc., pp. 657-785.

20 Gauss, opus cit., Dritter Teil, Zweite Hälfte, pp. 208-260.

21 Barker, opus cit., pp. 338-363.

22 Jaeger, obra y traducción citadas, pp. 1015-1077.

23 Guthrie, opus cit., V, pp. 321-381.

24 Leo Strauss, The Argument and the Action of Plato's Laws, The University of Chicago Press, Chicago and London, 1975.

25 Léon Robin, Platon, Oeuvres Completes. Bibliothèque de la Pléiade, Tomo II, Pp. 635-1131.

26 Platon, Les Lois. Tome XI - 2e. Partie. Trad. Edouard des Places. Col. Budé.

27 Plato, Laws. With an English Translation by R. C. Bury. The Loeb Classical Library.

28 Plato, The Laws. Translated with an Introduction by Trevor J. Saunders. Penguin Books.

20 Cairns, opus cit., chapter II, pp. 29-76. 


\section{GAPITULO I}

\section{PRIMER LIBRO DE LAS LEYES}

\section{Estructura temática}

En el libro inicial de su extenso tratado, Platón discute cinco grandes temas: 1) el del origen y finalidades de la legislación; 2) el de las instituciones básicas y los fines últimos de las leyes de Esparta y Creta; 3) el de la definición de la paideia; 4) el de las virtudes y su jerarquía, con especial referencia a la bravura y la templanza; 5) el del valor educativo de la costumbre de los simposios.

Esta pluralidad de asuntos produce a primera vista la impresión de que el libro con que las Leyes comienzan es - como a juicio de varios críticos otros de la misma obra - un desordenado tratamiento de cuestiones cuya conexión interna difícilmente se advierte. El reproche no se justifica, porque un estudio cuidadoso revela que la disparidad de los tópicos que el autor aborda es sólo aparente, y que entre ellos existe, como esperamos ponerlo en claro más tarde, un enlace correcto y una adecuada trabazón doctrinal.

2. Sobre el presunto origen divino de las leyes de Esparta y Creta

La primera pregunta que el ateniense hace a sus compañeros de peregrinación es ésta: "¿Quién entre vosotros ha tomado para sí la responsabilidad de instituir las leyes? ¿Un dios o alguno de los hombres?"

Clinias le responde:

"Un dios, extranjero, un dios, como del modo más justo suele decirse. Entre nosotros, Zeus; en Lacedemonia, de donde viene Megilio se afirma, creo, que es Apolo".1

Volviéndose hacia el de Creta, el ateniense le recuerda que según Homero Minos acudía periódicamente a la cita que le daba su padre, a fin

1 Leyes, $624 a$. 
de formular, de acuerdo con los oráculos de éste, las leyes de sus ciudades. ${ }^{2}$

La forma en que el diálogo principia no puede ser más feliz. Si, en consonancia con la tradición, las leyes dóricas tienen un origen divino (lo que implica que son las mejores), resulta simbólico que el viejo ateniense y sus dos acompañantes se dirijan, como según la leyenda Minos lo hacía cada nueve años, a la gruta y al santuario de Zeus, porque el propósito de aquéllos no es sólo entretenerse durante el camino conversando sobre temas de política y legislación, sino, como se infiere de lo dicho por Clinias al final del tercer libro, ${ }^{3}$ inquirir de qué manera será posible regular legalmente, con eficacia y justicia máximas, la vida de los moradores de la polis que los cretenses han decidido fundar.

Las viejas leyes de Esparta y Creta no son únicamente las más sabias por el origen que Megilio y Clinias les asignan, sino también, y ésta era la creencia de los griegos, porque "si lo viejo es lo bueno, lo mejor es lo más añejo; y, para que sea simplemente superior a lo que se ha originado más tarde, lo más antiguo tiene que ser sobrehumano y divino"." Aunque se asegure que lo que "es obra de los dioses, no siempre es lo mejor", porque, como lo relata Homero, Zeus dio a Creta sus leyes, pero se las dio a través de Minos, y ni el poeta ni los cretenses "son los garantes de la justicia de Minos"."

La piadosa creencia en la santidad de las normas ancestrales no excluye la posibilidad de que los legisladores humanos depositarios de la revelación la interpreten en forma incorrecta y no siempre sean capaces de convertirla en contenido de un ordenamiento legal intrínsecamente justo.

El ateniense no quiere discutir la afirmación de Clinias sobre la autoria de las leyes de su pais; y, aunque parece aceptarla, ello no obstaculiza el propósito del primero de investigar con sus acompañantes si las normas y costumbres de los dóricos, en cuanto obra humana, son irreprochables. ${ }^{6}$

2 Ibidem, 624a-624b.

3 Ibidem, 701c-e.

4 Strauss, opus cit., p. 3.

5 Idem.

6 Conviene tener presente, sin embargo, que "muchos rasgos del Estado platónico están tomados directamente del modelo espartano o se revelan como instituciones espartanas traducidas por el filósofo a una forma espiritualizada y superior. Por este procedimiento podrá pensarse fácilmente que el paso que va de la idea espartana a la idea platónica del Estado es un paso relativamente corto. La Esparta idealizada de la República platónica proyecta un rayo de transfiguración sobre el modelo terrenal". Jaeger, obra y traducción citadas, p. 1022. 


\section{Sobre los principales objetivos de la legislación cretense}

Para emitir un juicio sobre los méritos del orden legal de una polis no es necesario conocer en detalle el contenido de las prescripciones que lo integran; basta con esclarecer cuáles son las grandes finalidades que, a

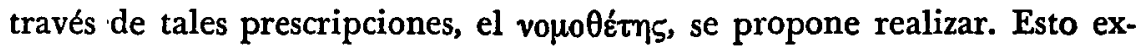
plica que el ateniense pregunte a Clinias: "¿Con qué propósito la ley ha prescrito entre vosotros las comidas en común, los gimnasios y el equipo bélico de que os servis?"." No se trata, si deseamos hablar con rigor, de una, sino de tres preguntas, cada una de las cuales está referida a un aspecto característico de las costumbres dóricas. Clinias expone, en primer término, lo relativo al equipo bélico de que los cretenses hacen uso:

"Entender nuestras costumbres, extranjero, es fácil para cualquiera. Bien veis cuál es la índole del terreno en toda Creta; no es un país de llanuras, como el de los tesalios. Por ello, también, éstos se sirven principalmente de los caballos, mientas que nosotros preferimos la carrera a pie. Aquí, en efecto, el suelo es accidentado y, en consecuencia, se presta más para ese género de ejercicio. En un terreno como el nuestro es necesario emplear armas ligeras, a fin de poder correr sin una carga pesada; así que la ligereza de los arcos y las flechas parece lo más conveniente. Todo ello nos ha preparado para la guerra y, en mi opinión, el legislador ha dispuesto todas estas cosas en vista de tal fin." 8

El mismo propósito permite explicar la costumbre de las comidas en grupo. Lo que llevó al legislador a establecerlas fue la observación de que en todos los pueblos, cuando las tropas están en campaña, el cuidado de su propia seguridad obliga a los soldados a comer reunidos mientras no terminen las hostilidades.

Nuesto legislador - prosigue Clinias - pretende con ello condenar el error de la mayor parte de los hombres, los cuales parecen no darse cuenta de que entre todos los Estados existe una guerra perenne, y de que es indispensable que en épocias de beligerancia los combatientes coman juntos y haya siempre jefes y soldados que velen por la patria. Mas no sólo cuando se lucha; también en los llamados tiempos de paz es necesario que cada ciudad aumente su poderio, a fin de estar en condiciones de repeler cualquier ataque. Lo que comúnmente se llama paz no es tal sino de nombre; y en realidad, sin que medie ninguna declaración de guerra, los países se mantienen armados en todo momento, para prevenir el riesgo de una agresión. La política de nuestros legisla-

7 Leyes, $625 c$.

8 Ibidem, 625c-e. 
dores descansa en el supuesto de ese continuo estado de amenaza, por lo cual, al emitir sus leyes, han querido hacernos comprender que ni la fortuna, ni el cultivo de las artes, ni ningún otro de los bienes, nos servirá de nada si no somos los más fuertes, porque la victoria en las contiendas transfiere a los que triunfan las riquezas de los vencidos. ${ }^{\ominus}$

El ateniense interrumpe a Clinias para expresar, de inmediato, su desacuerdo. A fin de poner al desnudo la inmoralidad de los propósitos de conquista y predominio, pregunta a su interlocutor si la máxima de los legisladores cretenses, referida por ellos a las relaciones entre los Estados, vale asimismo para las que existen entre aldea y aldea, familia y familia, individuo e individuo y también, por qué no, respecto de los conflictos que a veces surgen, dentro del pecho de cada hombre, entre las encontradas tendencas de su propia naturaleza.

Sin advertir cuál es el punto a que el ateniense quiere llegar, Clinias le asegura que ha proyectado una nueva luz sobre el tema que han venido discutiendo, y que, por haberse elevado hasta el principio del debate, a su codialogante le será más fácil percatarse de que todos somos enemigos de todos, así los Estados como los particulares, y de que cada hombre está en guerra contra sus malos deseos. ${ }^{10}$

El de Atenas pide a Clinias que explique con mayor diafanidad su pensamiento.

"La primera y más excelente de las victorias, extranjero -responde el cretense-, es la que obtenemos sobre nosotros mismos, y la más vergonzosa y funesta de las derrotas la de aquel que por sí mismo es vencido; lo cual significa que en cada uno de nosotros puede producirse una guerra intestina." 11

- Si cada persona es o superior o inferior a sf misma -argumenta el extranjero- ¿vamos por ello a sostener que lo propio ocurre en una casa, una aldea o una ciudad?

-Tu pregunta es excelente - contesta Clinias- pues es muy cierto que así sucede, sobre todo en las ciudades. "En efecto, dondequiera que los mejores se impongan a la multitud y a los peores, con razón podrá decirse que la polis es superior a sí misma, y tal victoria será, del modo más justo, alabada; y lo contrario ocurrirá cuando lo contrario acontezca." 12

-Si he comprendido bien lo que acabas de expresar - declara el extranjero- es posible que ciudadanos oriundos de una misma polis, "uniendo su injusticia y sacando provecho de su número, hagan violen-

Ibidem, $626 b$.

10 Ibidem, $626 d$.

11 Ibidem, 626e.

12 Ibidem, $627 a$. 
cia y esclavicen a la minoría de los justos. Si aquéllos llegan a triunfar, con razón podrá afirmarse que la polis es, a un tiempo, inferior y mala; si los primeros son vencidos, habrá que sostener, en cambio, que es buena y superior a sí misma". ${ }^{13}$

- Tu aserción - comenta Clinias - ciertamente es extraña; pese a ello, tendremos que admitirla tal como ha sido formulada.

- Examinemos ahora el caso de varios hermanos nacidos del mismo padre y de la misma madre. De acuerdo con lo que has expuesto - dice el de Atenas- es posible que de esos hermanos unos sean perversos y los otros no. Si los malos son los más fuertes, la familia a que pertenecen tendrá que ser considerada como inferior a sí misma; si lo contrario ocurre, habrá en cambio que aseverar que es buena y superior a sí misma. Preguntémonos ahora: ¿no sería correcto suponer que los jóvenes de nuestro ejemplo tuvieran un juez? $\mathrm{Y}$, de existir éste, ¿no podríamos, con toda razón, inquirir cuál sería el mejor? ¿El que, de esos hermanos, hiciese morir a aquellos que fuesen malos, ordenando a los buenos que se gobernasen por sf mismos, o el que asignando toda la autoridad a los buenos, perdonase la vida a los otros, después de haberlos exhortado a que se sometiesen voluntariamente a los virtuosos?... Mas si un tercer juez, con el deseo de poner remedio a las disensiones de la familia sin hacer morir a nadie, encontrase la manera de apaciguar a los hermanos y conseguir que fuesen amigos, haciéndoles observar ciertas leyes, no hay duda de que aventajaría con mucho a los otros dos. ${ }^{14}$

—iEse juez, ese legislador —exclama Clinias— sería, sin comparación, el mejor de todos!

- Pero entonces - concluye el ateniense - al dictar sus leyes tendría que inspirarse en un propósito diametralmente opuesto al de la guerra. Por tanto, habrá que reconocer que "el mayor bien no es la guerra ni es la sedición: desearlas resulta detestable; lo mejor es que la paz y los sentimientos de benevolencia recíproca reinen a la vez entre los ciudadanos. Por ello, según parece, la victoria de una ciudad sobre la misma no debe incluirse en el número de los bienes mayores, sino en el de los necesarios. ¡Hacer otra cosa sería tanto como creer que un cuerpo enfermo y purgado por un médico se halla en la mejor condición posible, sin dirigir siquiera el pensamiento a la del organismo que ninguna necesidad tiene de remedios! El que discurriera de tal modo respecto de la felicidad de la polis o de la de un simple particular, jamás llegaría a ser un buen político o un legislador concienzudo, si, poniendo primera o exclusivamente su atención en los conflictos externos, no legislara sobre la

13 Ibidem, $627 b$.

14 Ibidem, 627c-628e. 
guerra en vista de las cosas de la paz, en vez de legislar sobre la paz en vista de las cosas de la guerra. ${ }^{16}$

-Tus palabras son muy sensatas; - declara Clinias- pero, o mucho me equivoco, o nuestras leyes, al igual que las de Lacedemonia, no se ocupan únicamente de lo que a la guerra atañe.

-Quizás sea como dices - responde el ateniense- mas no es ocasión ésta de censurar a vuestros legisladores. Interroguémonos apaciblemente, como si su fin y el nuestro coincidiesen, y prosigamos nuestro diálogo. Recordemos al poeta Tirteo, ${ }^{16}$ nacido en Atenas y recibido como ciudadano en Esparta, hombre que más que nadie ha exaltado las virtudes guerreras, como lo prueban los versos en que dice: "Juzgo indigno de elogio y tengo en nada... al que no descuella en los combates, aunque fuese el más rico de los hombres y tuviese incontables bienes." ${ }^{18}$ Dirijámonos, pues, los tres a él para decirle: 'Tirteo, divinamente inspirado poeta, sin duda has dejado ver tu sabidurfa y tu talento al colmar de loas a los que se han distinguido en las batallas. Tus alabanzas son justas; pero quisiéramos saber si tus elogios y los nuestros recaen sobre las mismas personas'. Dinos, pues, ¿estás de acuerdo con nosotros en que existen dos géneros de guerra? Seguramente convendrías en que una de ellas, llamada sedición, es la más cruel de todas, y en que la segunda es aquella que se emprende contra otras naciones. ¿De cuál hablabas tú, y a qué hombres querías alabar o vituperar? Pensamos que te referías a las externas, porque en tus poemas dices que no soportas “a los que no se atreven a mirar cara a cara a la sangrienta muerte, ni a llegar a las manos con el enemigo". Nosotros, por el contrario, sin dejar de hacer justicia a tus guerreros, pretendemos que deben ser preferidos los que ganan honra en la otra especie de lucha, la más violenta, e invocamos como testigo a Teognis, ${ }^{18}$ ciudadano de Mégara en Sicilia, que dice:

"Cirno, el hombre fiel en la sedición es más valioso que el oro y la plata".

El que se mantiene fiel cuando la revuelta estalla supera tanto a los guerreros de Tirteo cuanto a la justicia, la prudencia y la templanza, que unidas a la fuerza, aventajan a la fuerza sola. La prueba está - prosigue el ateniense- en que un hombre únicamente puede ser leal a la

15 Ibidem, 628c-628e.

16 Sobre el poeta Tirteo, cf. Alfred et Maurice Croiset, Histoire de la Littérature Greque, Tome Second, Paris, Alfred Fontemoing, éditeur, 1898, pp. 102-112.

17 Leyes, 629a-629b.

18 Ibidem, 629c-630a. Sobre Teognis, cf. Alfred et Maurice Croiset, obra y tomo citados, pp. 133-155. 
patria en las horas críticas cuando posee todas las virtudes. Entre los soldados mercenarios, en cambio, muchos de los cuales son insolentes, disolutos o injustos, suele haber no pocos que en los cambates, como dice Tirteo, valerosamente "se enfrentan a la sangrienta muerte". Todo buen legislador y sobre todo los que como el de Creta han sido adoctrinados por la divinidad, necesariamente se proponen en sus leyes, como meta última, infundir en los ciudadanos un sentimiento de fidelidad a las instituciones de la polis, virtud a la que con todo derecho podría otorgarse el calificativo de "justicia perfecta". ${ }^{10}$

De este modo - afirma Gomperz- Platón "tiende un puente entre la política y la ética". Si la guerra y la conquista no constituyen la aspiración más alta del Estado, "¿cómo podríamos asignar a la bravura el primer sitio en el conjunto de las virtudes?" Las leyes cretenses, tan alabadas por Clinias, se hallan solamente dirigidas a una parte de la \&eetŕ, la menos valiosa, en vez de orientarse, en la medida en que persiguen propósitos educativos, hacia el fomento de la virtud total. ${ }^{20}$

Para apoyar su aserto de que la avóeía no es la excelencia moral suprema, el ateniense emprende una digresión sobre el orden jerárquico de los bienes: éstos son de dos clases, "unos humanos, otros divinos. Los primeros dependen de los divinos, y quien recibe los segundos adquiere también los bienes menores; de lo contrario, pierde unos y otros. De los menores se piensa que el primero es la salud; la belleza, el segundo; el tercero, la fuerza en la carrera y en los demás movimientos corporales y, el cuarto, la riqueza; mas no la que está ciega, sino la de vista penetrante que busca siempre la sabiduría por compañera. El primero, en la escala de los bienes divinos, es la sabiduría; el segundo, unido a la inteligencia, la templanza de las disposiciones del alma; el tercero, cuando los anteriores se mezclan con el valor, la justicia y, el cuarto, la valentia. Todos ellos tienen, de acuerdo con su naturaleza, mayor altura que los humanos, y el legislador debe también jerarquizarlos asi". ${ }^{21}$

"Los bienes superiores - comenta Jaeger - llevan siempre implícitos, como ya decia Teognis de la justicia, los bienes o virtudes inferiores. $Y$ la verdadera unidad que los abarca a todos, los divinos y los humanos, es la frónesis, la areté del espiritu. Con esta declaración, Platón supera todos los conceptos de virtud establecidos, uno tras otro, por los primeros poetas griegos." 22

19 Leyes, 630b-c.

20 Gomperz, opus cit., p. 488 del tomo segundo.

21 Leyes, 631b-631d.

22 Jaeger, opus cit., p. 1025 de la traducción castellana. 


\section{Definición de la paideia}

Las críticas que en forma tan cuidadosamente cortés hace el de Atenas a las leyes dóricas, recaen principalmente sobre la deficiencia de sus propósitos educativos. No podría ser de otro modo, ya que, para el ateniense, el primer educador de los ciudadanos es el encargado de darles leyes. Tal certidumbre domina todas las consideraciones que el principal de los interlocutores de la extensa obra formula al dirigirse a los otros dos.

Si deseamos saber cómo ha de definirse la paideia, preciso será no olvidar que "el hombre que se proponga sobresalir en cualquier tarea, tendrá que dedicarse a ella desde la infancia, ${ }^{23}$ practicando siempre, a manera de juego o con seriedad, cada uno de los actos que con la misma se relacionen. El que quiera ser un buen arquitecto o un buen agricultor, deberá divertirse construyendo esas casitas que hacen los niños o cultivando la tierra; y el educador de entrambos les regalará pequeños útiles, remedo de los verdaderos. Además, procurará que aprendan todas las cosas cuyo conocimiento previo es indispensable; el futuro carpintero, por ejemplo, se ejercitará, jugando, en medir y nivelar; el futuro combatiente, en el arte bélico o en algún otro ejercicio de parecida indole. En una palabra: habrá que tratar, con ayuda de pasatiempos, de dirigir los gustos e inclinaciones de los educandos hacia aquello que a la postre podrá conducirlos al cumplimiento de sus fines. Lo esencial de la paideia consiste en la recta formación que por medio de entretenimientos adecuados, hará que el alma del niño ame las actividades en que le será necesario, cuando sea mayor, alcanzar en su profesión el máximo grado de excelencia". ${ }^{24}$

-Vuestras leyes son muy sensatas - dice el ateniense a Clinias y a Megilio- y, a mi juicio, una de las mejores es la que prohíbe a los jovenes escudriñar lo que de bueno o defectuoso pueda haber en las prescripciones del legislador, ordenándoles, por el contrario, que en toda ocasión proclamen que esas leyes son las más hermosas (por ser obra de los dioses), y que jamás den ofdos a quienquiera que delante de ellos se exprese en otra forma. ${ }^{25}$ Como ningún joven interviene en este diálogo y nuestra edad nos permite hacer uso de la licencia que concede a los viejos el legislador de Creta, no pecaremos contra sus normas si nos comunicamos, a solas, nuestros pensamientos sobre esta materia. Por lo

${ }^{23}$ Recuérdese la tesis, defendida por Sócrates en el libro IV de la República, según la cual cada hombre debe dedicarse siempre a aquella actividad para la que lo dotó mejor la naturaleza.

24 Leyes, 643b-643d.

25 Ibidem, 634d-634e. 
demás, no me atrevería a censurar vuestras leyes sino después de haberlas examinado con toda la atención de que me juzgo capaz. Sois los únicos, no sólo entre los griegos sino entre los bárbaros de que tengo noticia, a quienes el vouotétns ha vedado el uso de las diversiones y los placeres más vivos; $y$, en lo que respecta a las fatigas, los peligros y el dolor, juiciosamente ha creido que si desde la niñez nos aplicamos a evitarlos, cuando más tarde nos veamos por necesidad expuestos a ellos, vencerlos nos será más fácil. Me parece, sin embargo, que vuestro legislador debra haber tenido igual propósito respecto de los placeres, pues si, desde sus primeros años, el hombre no aprende a dominarlos, ejercitándose así en la virtud de la templanza, en lo porvenir será incapaz de resistir a su atracción, y acabará por convertirse en su esclavo. Mencionemos cuáles son en nuestras ciudades "las costumbres que inducen a gustar y no huir de los placeres, y, del mismo modo, cuáles las que, lejos de instigar a la evitación de los sufrimientos, constriñen a los ciudadanos a vivir entre ellos $y$, valiéndose de las recompensas como instrumentos de persuasión, los preparan para imponerse al dolor. ¿Es posible encontrar en vuestras leyes el mismo criterio en lo que concierne a los deleites? Decidme cuál es ese temple que entre vosotros hace a los mismos ciudadanos igualmente valerosos contra los sufrimientos y contra los goces, convirtiéndolos en vencedores de lo que hay que vencer y nunca en inferiores a sus enemigos más cercanos y temibles".

Megilio responde que aun cuando podría citar numerosas leyes que ayudan a luchar contra el dolor, en el caso de los placeres no le es posible ofrecer ejemplos importantes y diáfanos, ya que los que recuerda no merecen que se les tome en cuenta.

- "Tampoco a mí - confiesa Clinias - me sería posible señalar en las leyes de Creta ejemplos conspicuos de tal especie." 26

-Lo que decís no es extraño - afirma el de Atenas. "Y si alguno de nosotros, movido por el deseo de descubrir lo verdadero y lo óptimo, censurase algo en las leyes de cada una de nuestras ciudades, no tomemos a mal sus críticas, sino aceptémoslas con calma." ${ }^{27}$

-Tienes mucha razón, extranjero —responde Clinias- debemos hacer lo que dices.

El ateniense recuerda que anteriormente habían convenido en que los hombres de bien son aquellos que ejercen un absoluto dominio sobre sí mismos, y los malos los que no lo ejercen. Para desenvolver con amplitud esta tesis, pide a sus interlocutores que, con ayuda de una imagen, le permitan explicarse mejor.

-Aun cuando sabemos que cada hombre es uno, no por ello igno-

26 Ibidem, 634a-634b.

27 Ibidem, 634c. 
ramos que en su interior viven dos insensatos consejeros, entre sí enemigos: el placer y el dolor. Pero, además de éstos, cada persona alberga en su fuero interno ciertas opiniones sobre el futuro que designamos con el nombre común de espera, "pero con el especial de temor si del sufrimiento se trata, y el de confianza si la espera se refiere a lo contrario; y, por encima de todo ello, un cálculo que al transformarse en opinión común de la polis se llama ley". ${ }^{28}$

Sus codialogantes declaran que no entienden bien lo que el ateniense quiere decir, por lo que éste les propone que consideren la cuestión de esta manera. "Representémonos a cada uno de los seres vivientes que somos nosotros como un títere modelado por los dioses, ya sea como objeto de diversión, ya con un propósito serio, pues acerca de esto nada sabemos; mas lo que sí sabemos es que las afecciones que hay en nuestro interior son como cuerdas o hilos que tiran de nosotros, cada uno por su lado y, en virtud de la oposición de sus fuerzas, nos empujan hacia acciones contrarias, siendo aquí donde se halla la línea que separa a la virtud del vicio. Es necesario, indica el razonamiento, que cada uno obedezca siempre a una sola de las tracciones y en ningún caso se substraiga a ella, resistiendo así a las otras cuerdas. Aquélla es la del sagrado y áureo hilo de ese cálculo razonado que llamamos ley común de la ciudad. Los otros tienen la rigidez del hierro y asumen toda clase de formas, mientras que el primero es uniforme y flexible, precisamente por ser de oro. Se debe, pues, cooperar con la excelente tracción de la ley; pues aunque el cálculo de la razón sea bello, suave y nada violento, su tracción necesita ayudantes, a fin de que el linaje de oro venza en nosotros a los de plata y bronce. ${ }^{29}$ Esta manera de representarnos a nosotros mismos como una máquina animada explica muy bien lo que significa eso de que el hombre puede ser o superior o inferior a sf mismo, y hace ver que todo aquel que sepa cómo deben moverse esos diferentes hilos, ha de ajustar a tal conocimiento su conducta." so

28 Idem.

29 Leyes, 644c-644d.

30 Ibidem, 644d-645a. Las últimas palabras de la cita aluden al famoso mito de los metales, que Platón expone en el libro tercero de la Repuiblica, 414b-414e. 
5. Sobre las virtudes y su jerarquia, con especial referencia a la bravura y a la templanza ${ }^{31}$

Aun cuando en $631 b-d$, al exponer su clasificación de los bienes, ${ }^{32}$ Platón incluye entre los divinos las cuatro virtudes que reciben los nombres de sabiduría, templanza, justicia y bravura, sólo estudia con detenimiento, en las páginas del primer libro de las Leyes, las mencionadas en segundo y cuarto lugar. Tal limitación viene impuesta por el diálogo del ateniense con sus dos acompañantes y, sobre todo, por las censuras de aquél a las instituciones dóricas relativas a la guerra y a la elevación de la ávôeía al primer sitio de la escala axiológica.

En el libro inicial de su largo tratado, el autor no ofrece, como en el Laques $^{33}$ y en la República, ${ }^{34}$ una definición de la valentía; pero, de acuerdo con su tesis de que esta virtud se manifiesta de diversas maneras en las dos especies de guerra que el ateniense distingue, muy fácil le resulta dirigir un primer reproche a la idealización que del arrojo en las batallas hace en sus versos el poeta Tirteo. ${ }^{35}$ Mucho más nefastas que las contiendas entre ciudades son las de carácter interno que desig. namos con los nombres de sedición o guerra intestina; y más elevado aún que el de la intrepidez de los guerreros cantados por Tirteo, es el del valor del hombre que se mantiene leal cuando la revolución estalla, o el de aquel que, combatiendo contra las tendencias inferiores de su naturaleza, logra salir airoso de esta lucha.

En consonancia con su aserto de que en el alma del hombre moran "dos consejeros insensatos, entre sí enemigos", Platón pone en labios del ateniense esta pregunta: "¿A cuál de los dos llamaremos malo, al hombre que se deja vencer por el dolor o al que deja que el placer lo domine?"

- Opino que a este último _responde Clinias_ pues todos sabemos

31 "En este pasaje, como en toda la obra en general -comenta Jaeger- Platón se muestra muy interesado en la concatenación psicológica a través de la cual actúa el principio supremo sobre el alma del hombre. Y la ilustra por medio de la imagen ( de la vida. Pero, ya hayamos sido creados como un simple juguete de Dios o para una elevada finalidad - pues esto no podemos saberlo nosotros mismos-, lo cierto es que los impulsos y las representaciones de nuestra alma constituyen los hilos que tiran de nosotros en diversas direcciones. Mientras que la perspectiva de gozar un placer o sentir un dolor mueve nuestra vida instintiva en forma de sentimientos de

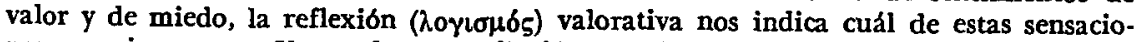
nes es mejor o peor. Y cuando esta reflexión constituye un acuerdo común de la polis, la Ilamamos ley." Paideia, p. 1030 de la traducción castellana.

32 Leyes, 631b.d.

33 Cf. Laques, 194e-195a.

34 Cf. República, libro IV, 429c.

35 Leyes, 630d-e. 
que el que cede al placer es más vergonzosamente inferior a sí mismo que el que sucumbe al dolor."

-Entonces -inquiere el de Atenas - ¿vamos a sostener que los legisladores de Zeus y Apolo han formulado sus leyes para una hombría coja, capaz de resistir sólo por el lado izquierdo, pero incapaz de enfrentarse a las amables seducciones que por el lado derecho la amenazan? ¿O debemos responder más bien que puede resistir por ambos lados?" ${ }^{36}$

La manifestación más depurada de la ávôezía no es, pues, la del soldado que da la cara con denuedo a los enemigos de su patria, sino la del hombre que victoriosamente se opone a sus pasiones más bajas. ${ }^{37}$

Todo legislador digno de este nombre, como el de Creta, a quien el mismo Zeus adoctrinó, no formulará sus leyes para inculcar en los ciudadanos una sola virtud, que no es por cierto la más alta, sino con el propósito de que aspiren a esa suprema excelencia que resulta de la unión de la justicia con la sabiduría, la templanza y la fuerza. ${ }^{38}$

$Y$ cuando Clinias objeta que estas palabras encierran una censura a los legisladores de Creta y Lacedemonia, el ateniense replica que el reproche no alcanza a Minos ni a Licurgo, porque no va dirigido contra las leyes de éstos, sino contra la interpretación que de las mismas se hace.

-Si ahora - prosigue el ateniense - pasamos de la bravura a la templanza, ¿qué encontraremos sobre este particular, como hace un momento sobre la guerra, que esté mejor reglamentado en vuestros Estados que en otros que no tienen buenas leyes?

Clinias asienta que, a su juicio, las comidas en común y los gimnasios sirven muy bien al propósito de inspirar a los ciudadanos lo mismo el valor que la templanza.

-Ambas instituciones -opina el de Atenas - son ventajosas en varios respectos; pero en el caso de la sedición, presentan serios inconvenientes, de lo cual "dan buena prueba los milesios, los beocios y los turianos". ${ }^{39}$ Además, la de los gimnasios ha producido un mal gravísimo al pervertir el disfru'te de los placeres del amor "que la naturaleza regula no sólo respecto de los hombres, sino también de las bestias. De estas perversiones vuestras ciudades son quizás las principales responsables, junto con todas aquellas que se entregan asiduamente a los ejercicios gímnicos. $\mathrm{Y}$ ya sea que se hable de esto en broma o en serio, en todo caso se debe considerar que tanto el sexo femenino como el masculino parecen haber recibido este placer de la naturaleza cuando se ayuntan en vista de la procreación, mientras que los contactos sexuales de hombres con hom-

36 Ibidem, 633e-634d.

37 Ibidem, 633d-633e.

38 Cf. Gomperz, obra y tomo citados, pp. 488 y 489.

39 Leyes, $636 b$. 
bres y de mujeres con mujeres resultan un atentado contra natura, sólo atribuible a la intemperancia de quienes por vez primera lo cometieron". ${ }^{40}$ "El placer y el dolor son dos fuentes naturales que nunca dejan de fluir. El Estado, el individuo o el animal que van a abrevarse en ellas en el momento y la medida adecuados, son dichosos; los que, por el contrario, beben de esas fuentes sin discernimiento y fuera de sazón, son desdichados." 41

-Lo que dices -opina Megilio_- es hasta cierto punto cierto; $y$, cuando buscamos qué podríamos oponer a tus censuras, nos sentimos en sumo grado perplejos. Pienso, empero, que no sin razón ha ordenado el legislador de Lacedemonia que se procure huir de los placeres. Lo que las leyes de Esparta disponen sobre este particular me parece aconsejable; ellas se han propuesto desterrar de todo el país cuanto ofrece a sus moradores la ocasión de entregarse a excesos de voluptuosidad o incontinencia. $\mathrm{Ni}$ en los campos ni en las ciudades espartanas se organizan banquetes ni nada de cuanto los acompaña y excita el deseo de toda clase de goces. Cuando un individuo bebe hasta el extremo de Ia ebriedad se le castiga severamente. Entre vosotros en cambio, en ocasión de las fiestas de Baco, he visto carretas llenas de borrachos, y, en-Tarento, a toda la ciudad sumida en la embriaguez el día de las bacanales. Nada semejante ocurre entre nosotros. ${ }^{42}$

Las aficiones de que hablas - responde el ateniense- nada tienen que no sea loable, si en ellas se observa cierta moderación. Por otra parte, mis coterráneos podrían devolveros la pelota, reprochándoos el libertinaje de vuestras mujeres. En Tarento, lo mismo que entre nosotros y entre vosotros, las costumbres de cada polis suelen ser distintas de las de las demás; cada una ha formado las suyas, y en ellas nada encuentra que le parezca reprochable. Pero, sobre todo, juzgo que no es éste el momento de discutir los hábitos y prejuicios del vulgo; lo que debe interesarnos son la cordura y la inteligencia de los legisladores. Os propongo, pues, que nos refiramos a los banquetes y a la ebriedad en general, para establecer, respecto de la misma, si hay que tratarla como lo hacen los escitas, los persas, los cartagineses, los celtas, los iberos y los tracios, naciones belicosas todas ellas, o como la tratáis vosotros, que os abstenéis totalmente del vino.43 


\section{Sobre el valor educativo de la costumbre de los simposios}

Al referirnos a la bravura afirmamos que a diferencia de lo que ocurre en otros diálogos, Platón no ofrece en las Leyes una definición de tal virtud. Lo propio podría decirse de lo que en la misma obra expone acerca de la templanza. No la define, si bien, del tratamiento que hace de ella, cabe inferir que la concibe como energía moral dirigida al dominio de uno mismo en todo lo concerniente a los placeres del vino, de la mesa y del amor, que es lo que en 430e del libro IV de la República asevera de la owpooór noción corriente de dicha virtud, sino que, comparándola con la sapiencia y la bravura, sostiene que se asemeja a una especie de armonia, porque su manera de obrar no es como la del saber o la del valor, que "existiendo cada uno en cierta parte de la polis, la harian, el uno, sabia; el otro, valiente". ${ }^{4}$ La templanza no actúa de tal manera, sino que abraza a todas las virtudes, "presentando unidos en un mismo coro a los más débiles, a los más fuertes y a los medianeros, séanlo por su prudencia, por su vigor o, también, por su número, su fortuna o algún otro de tales respectos" (431e-432a). Esta concordia de aquéllos es "el acuerdo de lo mejor y lo peor por naturaleza acerca de quién debe gobernar", tanto en la ciudad como en cada una de las almas.

Los pasajes de las Leyes en que el autor discute en qué consisten la àvopía y la $\sigma \omega \varphi \rho o v^{\prime} \eta$, revelan que no logra distinguirlas con suficiente claridad, puesto que declara que la forma más alta de la valentía no es la del guerrero que se enfrenta a la muerte en el campo de batalla, sino la del ciudadano que victoriosamente combate contra sus apetencias más bajas, ${ }^{45}$ lo que indica que para obtener el triunfo en esta lucha interior, el hombre se ve obligado a desplegar una virtud que más que parecerse a la de los guerreros de Tirteo, casi se confunde con otra más elevada, la de la templanza o autodominio. Lo que el filósofo dice de la owpeooúvn en su tratado de las Leyes demuestra que esta excelencia nunca está desligada de la àvóesia, porque, si una persona quiere volverse "superior a sí misma", tiene que oponerse valientemente a las fuerzas inferiores de su naturaleza.

La circunstancia de que en su obra Platón no profundice en el estudio de las cuatro grandes virtudes, y sólo trate con cierta extensión de las que en la escala axiológica ocupan los lugares segundo y cuarto, se explica en parte porque su propósito principal es hacer la critica de las leyes dóricas relativas a la guerra y a la $\pi \alpha \delta \varepsilon l a$. Su tesis sobre las dos es-

44 Repriblica, 431e-482a.

45 Leyes, 630a-630b. 
pecies de lucha, la extranjera y la intestina; las censuras que dirige contra las perversiones a que suelen dar origen los gimnasios y, sobre todo, el aserto de que la manifestación suprema de la valentía es la de aquel que sabe "vencerse a sí mismo", claramente subrayan la importancia que atribuye al arrojo y a la templanza, así como al papel que ambas virtudes desempeñan al servicio de los ideales educativos de la polis. La mejor prueba de todo ello la encontramos en los extensos desarrollos que emprende en los libros primero y segundo de las Leyes con el propósito de convencer a Clinias y a Megilio de que un simposio bien dirigido es una escuela de moderación.

El ateniense prepara sus argumentos con esta pregunta: los banquetes y los comensales que los componen, ¿no forman acaso una especie de asamblea?

Sus interlocutores asienten, y el de Atenas confiesa que rara vez hay orden en esas reuniones; que casi nunca las encabeza un hombre capaz de dirigirlas, y que, por regla general, los que en ellas se encuentran. incurren en toda clase de excesos. Yo he asistido a muchas -prosigue el de Atenas-y puedo aseguraros que no he visto una sola en que todo ocurriese regularmente. ¿No estaréis entonces de acuerdo en que no únicamente en las comidas en que se bebe vino, sino en toda especie de asamblea, cualquiera que sea su objeto, lo correcto es que haya un jefe? -Por supuesto.

$-Y$, ¿no aseverábamos hace un momento que el comandante de un ejército debe ser valiente?

- Lo aseverábamos, en efecto.

-Luego, "si dispusiésemos de algún medio para poner al frente de los soldados a un estratego que de nada tuviese miedo y no se estremeciese jamás, ¿no hariamos cualquier cosa para lograrlo?" Sólo que ahora no vamos a hablar del que manda un ejército, "cuando enemigos luchan contra enemigos en tiempos de guerra, sino del hombre que preside el banquete de un grupo de amigos deseosos de compartir, en tiempos de paz, sus sentimientos de recíproca benevolencia". ${ }^{46}$

-Lo que has dicho es verdad -declara Clinias- "pero explícanos qué provecho nos reportará esta institución de los simposios, si suponemos que se siguieran fielmente sus reglas".

-Si un niño o incluso un coro de niños fueran preparados como es debido -responde el ateniense_ ¿en qué diríamos que la ciudad se ha beneficiado? "A semejante pregunta sin duda responderíamos que cuando se trata de un solo caso poco es lo que la polis gana; mas si se inquiere, de manera general, cuál es para ella la utilidad de la educación de los pequeños, sin vacilar contestaríamos que los bien educados podrán

46 Ibidem, 640a-640b. 
convertirse en hombres valiosos, y que, de llegar a ser tales, harán bien todas las cosas... Veamos ahora si de la costumbre de los banquetes se puede afirmar lo propio. Pero, antes de ensayar una respuesta, preguntémonos si beber vino no excita y hace más intensos los placeres, las penas, la cólera y el amor, y no vuelve más vivos los recuerdos, las sensaciones y los pensamientos, aun cuando, en la mayoría de los casos, más bien ocurre que abandonan por completo al hombre saturado por la em. briaguez, haciendo que llegue al mismo estado en que se encontraba cuando era niño." 47

-De ello no hay duda - comenta su interlocutor.

-Luego, según parece, "no solamente el viejo puede ser dos veces niño, sino también el que se embriaga".48

Pero el hecho de que alguien llegue a tal extremo, o el de que en los banquetes sea frecuente que los comensales beban más de lo debido, no excluye la posibilidad de que tales reuniones, si son bien dirigidas por un jefe hábil y sobrio, sirvan al propósito de fomentar en los bebedores la virtud de la temperancia. Si pudiera probarse que la costumbre de los simposios "tiene para nosotros una utilidad no menor que la de los ejercicios gimnásticos -arguye el ateniense— claro sería desde un principio que supera a los últimos, ya que éstos van acompañados de dolores, y aquélla no".48

-Es cierto -admite Clinias_, mas no creo que sea fácil demostrar que los banquetes tengan la utilidad que pretendes.

- Precisamente para demostrarlo - contesta su interlocutor- quiero que me digas si es o no posible distinguir dos clases de temores, totalmente opuestos entre sí.

—AA qué te refieres? - demanda Clinias.

-Al temor de que ciertos males ocurran, así como al de que "se nos moteje de perversos si hacemos o decimos algo deshonesto". A este último le damos el nombre de vergüenza, y "tanto el legislador como todo hombre de valia" tienen al segundo en la mayor estima y, dándole el nombre de pudor, a la audacia opuesta le dan el de impudicia, "considerando que ésta es para todos, lo mismo en la vida pública que en la privada, el más grande de los males". ${ }^{50}$ Respecto de las manifestaciones del pudor -prosigue el de Atenas- "recordemos que hay dos cosas que nuestras almas deben cuidar con el mayor esmero: una, cómo podremos llegar a ser máximamente audaces; otra, cómo, por el contrario, podremos volvernos máximamente temerosos". ${ }^{51}$ Cuando nos encontremos en las cir-

47 Ibidem, 645d-645e.

48 Ibidem, 646a.

4 Ibidem, 646d.

50 Jbidem, 646e-647b.

51 Ibidem, 649b-649c. 
cunstancias que nos hacen excesivamente audaces, necesario será que hagamos todo lo posible para liberarnos de la impudicia y, también, para sentir el temor de atrevernos "a decir, padecer o ejecutar cualquier cosa que pueda causarnos sonrojo". A incurrir en semejantes faltas nos exponen la cólera, el amor, la incontinencia, la avidez, la cobardía, así como lo que nos embriaga con el placer y nos hace perder la razón. Para domeñar tales pasiones, ¿puede haber prueba más cómoda e inocente que la del vino? Y si en ello observamos las debidas precauciones, texiste entretenimiento más adecuado a tal efecto que el de los simposios? Nada es más provechoso que ponernos a prueba unos a otros por medio de una diversión en la que no se corre ningún peligro; y no hay nadie, "ni cretense ni otro alguno", para quien esta manera de sondear el alma ajena no sea sólo convenientísima, sino "la menos costosa, la más segura y la más corta de todas las experiencias". Además - concluye el ateniense- "lo que nos permite conocer más a fondo los caracteres es, sin duda, el medio más útil respecto del arte de volverlos mejores, lo cual constituye, según creo, uno de los objetivos de la política". ${ }^{2}$ 